\title{
The Effect of Position on the Realization of Second Occurrence Focus
}

\author{
Jason B. Bishop \\ Department of Linguistics, University of California, Los Angeles \\ j.bishopeucla.edu
}

\begin{abstract}
Previous authors have suggested that prenuclear second occurrence foci may be marked both by higher pitch and increased duration, unlike their post-nuclear counterparts which show only increased duration. Results are presented from a production study that finds no evidence of pitch prominence for prenuclear second occurrence foci. Given evidence from German, it appears that the realization of second occurrence focus may also be sensitive to position within the prenuclear domain.
\end{abstract}

\section{Introduction}

In English, semantic focus is typically marked by intonational prominence, most canonically by a pitch accent. One case which has been presented as an exception to this generalization, however, is that of second occurrence (SO) focus. A SO focus is a focused but repeated item, such as the second occurrence of vegetables in the now classic example in $1[3]$ :

(1) A: Everyone already knew that Mary only eats [vegetables] $]_{\mathrm{FOF}}$.

B: If even [Paul $]_{\text {FoF }}$ knew that Mary only eats [vegetables] sof, then he should have suggested a different restaurant.

In a typical production of $1 \mathrm{~B}$, the most prominent accent is on the first occurrence (FO) focus, Paul, while the SO focus vegetables lacks prominence. Much discussed in the semantics literature [e.g., 1,2,3], this apparent mismatch between semantic focus and intonational prominence poses problems for several current theories of focus interpretation.

Recent experimental studies of SO focus, suggest that the mismatch is only apparent. In particular, [4] and [5] demonstrate that SO foci lack prominent pitch excursions, but are phonetically distinct from non-foci in terms of duration and intensity (albeit marginally; see also [6]). Why might $\mathrm{SO}$ foci lack pitch prominence? Note that in examples like 1B, the SO focus is situated after the nuclear accent on Paul. It is well-known that English intonation features postnuclear deaccenting, a process whereby pitch distinctions are lost following the nuclear accent in an intermediate phrase [7]. It has been proposed that SO foci lack the prominence of "typical" foci due to this post-nuclear deaccenting, a phonological rather than information structural explanation.

A post-nuclear deaccenting account, however, would seem to imply that prenuclear SO focus should be realized with pitch prominence. Indeed, in their study of German, [8] produce evidence in favor of this interpretation. They examine phonetic correlates of prominence for prenuclear SO focus as in $2 \mathrm{C}$ :
(2) A. Die meisten unseren Kollegen waren beim Betriebsausflug lässig angezogen. Most of our colleagues were dressed casually at the company outing.

B. Nur [Peter $]_{\mathrm{FOF}}$ hat eine Krawatte getragen. Only Peter wore a tie.

C. Nur $[\text { Peter }]_{\mathrm{SOF}}$ hat sogar einen $[\text { Anzug }]_{\mathrm{FOF}}$ getragen.

Only Peter even wore a suit.

Finding prenuclear SO foci to be realized with higher pitch, those authors argue, "Prenuclearly, fine-grained differences between accents are realized by pitch. Post-nuclearly, only duration is available because of deaccenting. Experiments investigating only post-nuclear SOF realizations have no chance at arriving at this conclusion. "'[8]: 22).

Additionally, they investigate the effect of utterance position on the realization of both SO and FO focused items, concluding the following:

(i) $\quad \mathrm{FO}$ foci are more prominent than both $\mathrm{SO}$ foci and non-foci in terms of pitch and duration

(ii) $\mathrm{SO}$ foci are more prominent than non-foci:

a. post-nuclearly in terms of duration only

b. prenuclearly in terms of both pitch and duration

(iii) Utterance-initial foci are more prominent than utterance-medial foci

The interests of the present paper center around (iib) and (iii). Although [8] report higher $\mathrm{f}_{0}$ for prenuclear SO foci, all prenuclear $\mathrm{SO}$ foci in their study appear as in $2 \mathrm{C}$, that is, early in the utterance (roughly, "utterance-initially"). It therefore remains an open question as to whether such prominence is also maintained by prenuclear, but utterancemedial SO foci. What follows is the description of a phonetic experiment which addressed this question.

\section{Production Experiment}

A production study was carried out to test for phonetic marking of SO focus in the prenuclear domain. Foci in this environment should be immune to the phonological effect of post-nuclear deaccenting, and previous research suggests that, at least when utterance-initial, they are pitch-prominent [8]. Of interest here is whether or not this is true for English prenuclear SO foci occurring later in the utterance.

\subsection{Stimuli}

Short discourses were designed to place monosyllabic test words before the nuclear pitch accent in the test sentences. Minimal and near minimal pairs for focus were formed by manipulating (via context) whether a noun in the syntactic 
scope of the focus sensitive operator only was SO focused or unfocused. Such a pair is illustrated by discourses 3 and 4 , below (see appendix for further examples):

(3) A. Just like he's hoping to do for Bruce's class today, Chad wanted to turn in both a graph and a chart to Pat.

B. But because he was short on time, Chad only turned in a [chart $]_{\mathrm{FOF}}$ to Pat today.

C. In that case, I think Chad will only turn in a [chart $]_{\mathrm{SOF}}$ to $[\text { Bruce }]_{\mathrm{FOF}}$ today.

(4) A. Chad wanted to turn in a chart for his projects for Bruce's class as well as Pat's

B. But because he was short on time, Chad only turned in a chart to $[\mathrm{Pat}]_{\mathrm{FOF}}$ today.

C. Actually, I thought Chad would only turn in a chart to $[\text { Bruce }]_{\mathrm{FOF}}$ today

In $3 \mathrm{C}$ chart is a SO focal item, whereas chart in $4 \mathrm{C}$ is not a focal item at all. Note that in both $3 \mathrm{C}$ and $4 \mathrm{C}$ the nuclear accent falls on Bruce.

In addition to stimuli containing noun test words, as in 3 and 4 , sentences with adjective-noun sequences were also used:

(5) A. Like she does for Sam, Molly often leaves a long note for Chad in the phonetics lab.

B. But sometimes Molly only leaves a [brief $]_{\mathrm{FOF}}$ note for Chad there.

C. By the same token, she sometimes only leaves a $[\text { brief }]_{\mathrm{SOF}}$ note for $[\mathrm{Sam}]_{\mathrm{FOF}}$ there.

(6) A. Molly likes to leave a brief note for both Sam and Chad in the phonetics lab.

B. But sometimes Molly only leaves a brief note for $[\mathrm{Chad}]_{\mathrm{FOF}}$ there.

C. On the other hand, she sometimes only leaves a brief note for $[\mathrm{Sam}]_{\mathrm{FOF}}$ there.

\subsection{Participants}

Five native speakers of American English ages 19 to 22 participated in the production study ( 2 male and 3 female). All five participants were UCLA undergraduates, none of whom reported any history of hearing, speech or communication disorders.

\subsection{Recording}

Stimuli were elicited in a communicative task. A computer screen displayed discourses like those above and the recording took place as follows: paired participants read and heard the first sentence (sentence $\mathrm{A}$, the context sentence). The first participant then read the next sentence (sentence B, the trigger sentence for focus), and the other read the last sentence (sentence $\mathrm{C}$, the test sentence) in response to the trigger sentence. Test discourses were interspersed among fillers and crucial pairs such as 3 and 4 were always presented at least four discourses apart. All five speakers were recorded digitally (22.05 $\mathrm{kHz}$ sampling rate) in a sound-attenuated booth in the UCLA Phonetics Laboratory. Nine paired test discourses were recorded (four with noun targets, five with adjective targets), five repetitions of each ( 9 test sentences $\times 2$ focus conditions $\times 5$ repetitions $\times 5$ participants $=450$ test items).

\subsection{Measurements}

The two phonetic correlates of prominence measured were duration and pitch (defined by $\mathrm{f}_{0}$ ). All acoustic analysis was done using Praat [9].

\subsubsection{Duration}

Test words were segmented using both waveforms and spectrograms. In addition to test words, reference words, chosen for their durational stability across utterances, were also measured. The same reference word (in most cases the verb) was used for both sentences in crucial pairs like those above. Thus it was possible to make direct comparisons of durations across the two focus conditions, as well as relative ones. This was desirable as it allows for some control for speech rate, and is another measure of local prominence. SO focused test words were compared with non-focused test words in two ways (where $\mathrm{T}=$ time in milliseconds):

$$
\begin{aligned}
& \text { a. Absolute: } \Delta \mathrm{T}_{\text {test word }} \\
& \text { b. Relative: } \frac{\Delta \mathrm{T}_{\text {test word }}}{\Delta \mathrm{T}_{\text {reference word }}}
\end{aligned}
$$

\subsubsection{Pitch $\left(f_{0}\right)$}

The maximum $\mathrm{f}_{0}$ value over the vowel was found for each of the test words for each focus condition. Additionally, the maximum $f_{0}$ was measured for reference words (the same used for duration). Again, there were two comparisons:

$$
\begin{aligned}
& \text { a. Absolute: } \mathrm{f}_{0} \mathrm{Max}_{\text {test word }} \\
& \text { b. Relative: } \frac{\mathrm{f}_{0} \mathrm{Max}_{\text {test word }}}{\mathrm{f}_{0} \mathrm{Max}_{\text {reference word }}}
\end{aligned}
$$

\subsection{Exclusion Criteria}

The data collected were subjected to the following criteria before being included in the analysis:

\section{A repetition is excluded if and only if:}

(i) the fluency of the sentence is interrupted (by a pause, stutter, cough, etc), or

(ii) the sentence is incorrectly read in terms of a segment or word, or

(iii) prominence is clearly given on the incorrect word in the trigger sentence (e.g., sentence B in 3 and 4), as judged auditorily by the author 
Criterion (iii) is particularly important, as sentence B was the trigger sentence for focus. That is, a test word can be a SO focus only if it was previously a FO focus. However this resulted in only a very a minimal number of exclusions. All repetitions passing (i) through (iii) were included in averages which were the units of analysis for each acoustic variable.

\subsection{Results}

\subsubsection{Duration}

Figures 1 and 2 show mean durations for test words for the two focus conditions. For the absolute comparison, SO focused test words were pronounced with longer duration compared with their non-focused counterparts by three of the speakers. When durations were considered relative to reference words, however, there was a significant effect for all but Speaker 1. Table 1 shows results of the paired t-tests used to compare means across focus conditions.

Figure 1. Absolute duration for SO focused and non-focused test words by speaker (mean and s.d.).

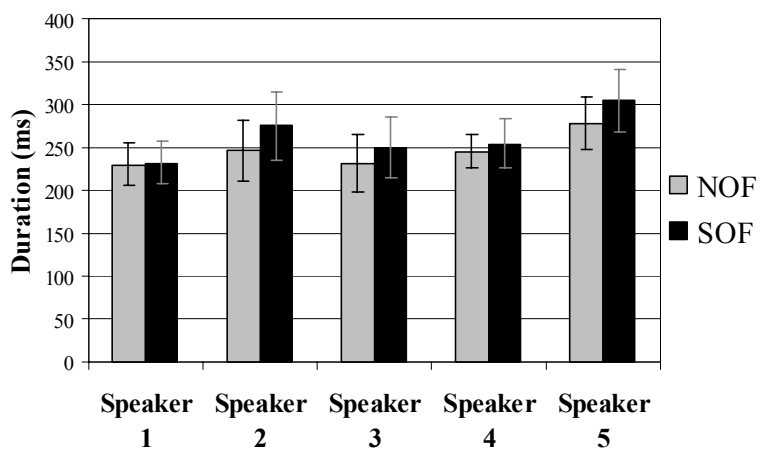

Figure 2. Relative Duration for SO focused and non-focused test words by speaker (mean and s.d.). Values show test words (TW) as a proportion of a reference word (RW)

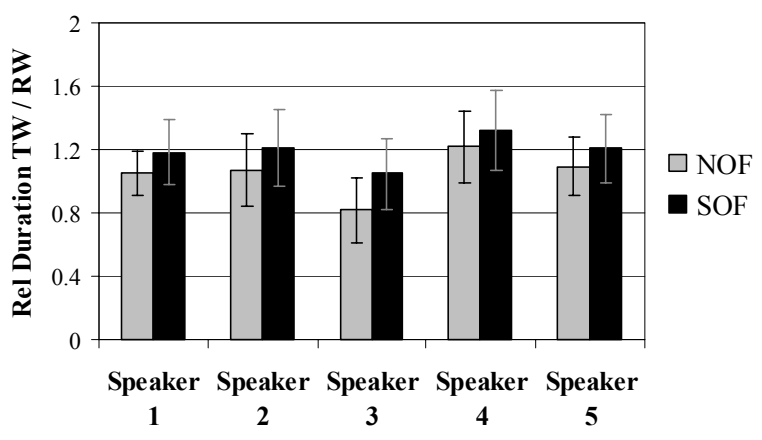

Table 1. Results of paired t-tests (2-tailed) for measures of duration (*indicates significant at $\alpha=.05$ ).

\begin{tabular}{|c|c|c|}
\hline & Absolute & Relative \\
\hline Speaker 1 & $\mathrm{t}(8)=.28, \mathrm{p}>.1$ & $\mathrm{t}(8)=2.0, \mathrm{p}=.08$ \\
\hline Speaker 2 & $\mathrm{t}(8)=4.8, \mathrm{p}<.001^{*}$ & $t(8)=3.4, p=.04 *$ \\
\hline Speaker 3 & $t(8)=2.4, p=.04 *$ & $t(8)=2.3, p=.05 *$ \\
\hline Speaker 4 & $\mathrm{t}(8)=.69, \mathrm{p}>.1$ & $t(8)=2.4, p=.04 *$ \\
\hline Speaker 5 & $\mathrm{t}(8)=5.8, \mathrm{p}<.001 *$ & $\mathrm{t}(8)=2.96, p=.02 *$ \\
\hline
\end{tabular}

\subsubsection{Pitch}

Pitch (i.e., average maximum $\mathrm{f}_{0}$ ) was considered for SO focused and non-focused test words for each speaker as was done for duration. Mean values are shown in Figures 3 and 4. Table 2 indicates that, unlike for duration, no significant differences were found for any of the participants.

Figure 3. Absolute F0 maximum for SO focused and nonfocused test words by speaker (mean and s.d.).

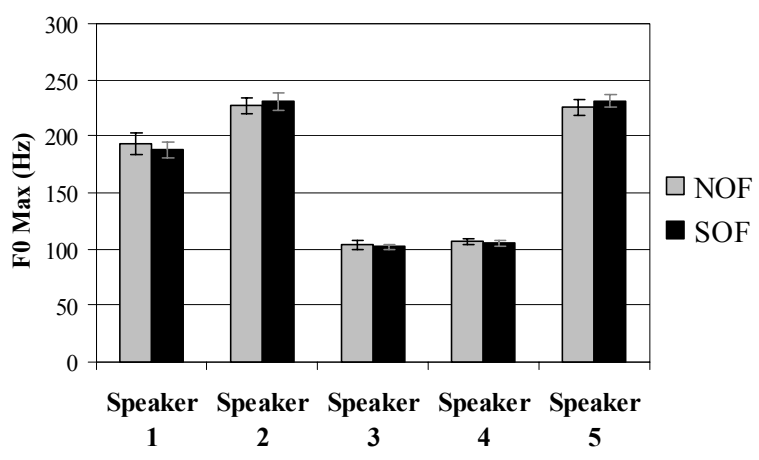

Figure 4. Relative F0 maximum for SO focused and non-focused test words by speaker (mean and s.d.). Values show test words (TW) as a proportion of a reference word (RW).

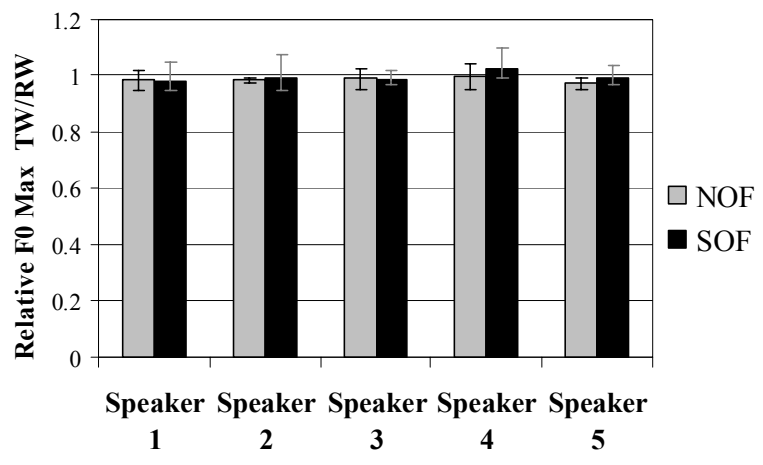

Table 2. Results of paired t-tests (2-tailed, $\alpha=.05$ ) for measures of $\mathrm{F} 0$.

\begin{tabular}{|l|l|l|}
\hline & \multicolumn{1}{|c|}{ Absolute } & \multicolumn{1}{c|}{ Relative } \\
\hline Speaker 1 & $\mathrm{t}(8)=1.4, \mathrm{p}>.1$ & $\mathrm{t}(8)=.2, \mathrm{p}>.1$ \\
Speaker 2 & $\mathrm{t}(8)=.9, \mathrm{p}>.1$ & $\mathrm{t}(8)=.4, \mathrm{p}>.1$ \\
Speaker 3 & $\mathrm{t}(8)=.5, \mathrm{p}>.1$ & $\mathrm{t}(8)=.07, \mathrm{p}>.1$ \\
Speaker 4 & $\mathrm{t}(8)=.95, \mathrm{p}>.1$ & $\mathrm{t}(8)=2, \mathrm{p}=.08$ \\
Speaker 5 & $\mathrm{t}(8)=1.6, \mathrm{p}>.1$ & $\mathrm{t}(8)=1.5, \mathrm{p}>.1$ \\
\hline
\end{tabular}

\section{Discussion}

Previous studies have demonstrated that SO focus lacks the prominent pitch excursion enjoyed by "ordinary" focus and it has been suggested $[5,8]$ that this fact is independent from its information structural status. Rather, it is thought to result from the post-nuclear deaccenting characteristic of English (and also German) intonational phonology. In the experiment described above, however, SO foci were positioned in an environment without post-nuclear deaccenting, and yet still there was no evidence for their pitch-prominence. Moreover, prenuclear SO foci were like post-nuclear SO foci in that they were distinguished from non-focal counterparts by increased duration. So while it is true that the post-nuclear environment is unfavorable to pitch distinctions [7,10], the results above indicate that an adequate account of $\mathrm{SO}$ focus realization will require more than deaccenting. 
An additional (also information structurallyindependent) factor may be position in the utterance. The authors in [8] found that SO foci were realized with more prominent $\mathrm{f}_{0}$ peaks when occurring early in the utterance (utterance-initially) rather than later (utterance-medially). In their German data, however, it was not possible to distinguish effects of utterance position -probably best regarded as phonetic- from the phonological effect of postnuclear deaccenting, as all prenuclear SO foci were utterance-initial and all utterance-medial were post-nuclear. In this study, prenuclear SO foci were utterance-medial and did not differ from non-foci in terms of pitch according to either the absolute or relative comparison. To be sure, these results can be compared to those for German in [8] only with great caution; any differences may be due not to position in the utterance, but simply because SO focus is realized differently in English than in German. However, given their quite similar intonational phonologies, particularly with respect to other aspects of SO focus, there is reason to believe it worthwhile to consider the results of the two studies side-by-side.

It is also worth noting that phonetic studies of SO focus, including the present one, have emphasized the role of $\mathrm{f}_{0}$ in defining pitch accents, more or less to the exclusion of other correlates of prominence. However, speakers make use of (at least) pitch, duration and intensity in making words prominent, and listeners perceive these parameters not separately, but in unison. Potentially of interest, then -but noticeably absent from the literature- is a more qualitative investigation of SO focus, such as a phonological analysis making use of ToBI transcriptions [11]. Such an analysis may reveal, for instance, that SO foci can be regarded as pitchaccented, but with a categorically different accent from that of FO foci (perhaps a ! $\mathrm{H}^{*}$ rather than a $\mathrm{H}^{*}$ ). Future work will look at such possibilities.

\section{Conclusion}

This study examined prenuclear second occurrence focus in English. A production study of five speakers was presented and discussed, the results of which showed prenuclear second occurrence focus to be marked with increased duration by four of the speakers, although no evidence of pitch marking was found for any speaker. If SO focus is ever marked by pitch in English, its realization may be crucially dependent on the inherent strength of the position in the utterance, as has been proposed for German.

\section{Appendix: Example Stimuli}

(i) A. Just like she does for her son Mark, Beverley usually leaves two things in Suzie's lunchbox: a treat and a little note.

B. But sometimes Beverley only leaves a [treat $]_{\mathrm{FOF}}$ in Suzie's lunchbox.

C. True, and sometimes she only leaves a [treat $]_{\mathrm{SOF}}$ in [Mark's $]_{\mathrm{FOF}}$ lunchbox. (ii) A. Always wanting to be fair, Beverley usually leaves a treat in both Suzie's lunchbox and Mark's lunchbox.

B. But sometimes Beverley only leaves a treat in [Suzie's $]_{\text {FOF }}$ lunchbox.

C. True, but sometimes she only leaves a treat in [Mark's $]_{\text {FOF }}$ lunchbox.

(iii) A. Just like he does for Russ when he goes to Europe, Dominique brought back both French wine and Italian wine for Ed yesterday.

B. But I thought Dominique only brought back [French $]_{\mathrm{FOF}}$ wine for Ed yesterday.

C. And in the same manner, he only brought back $[\text { French }]_{\text {SOF }}$ wine for $[\text { Russ }]_{\text {FOF }}$ yesterday.

(iv) A. Always thinking of his friends, Dominique wanted to bring back French wine for both Russ and Ed yesterday.

B. But I thought Dominique only brought back French wine for $[\mathrm{Ed}]_{\mathrm{FOF}}$ yesterday.

C. But on the contrary, he only brought back French wine for [Russ $]_{\text {FOF }}$ yesterday.

\section{Acknowledgements}

For her assistance with a number of aspects of this experiment, I am especially grateful to Natasha Abner. I also thank Sun-Ah Jun, Daniel Büring, Molly Shilman, Pat Keating, Melissa Wake and other members of the UCLA Phonetics Laboratory for helpful comments and suggestions.

\section{References}

[1] Büring, D., "Been there, marked that - a theory of second occurrence focus". Ms. UCLA. 2008.

[2] Rooth, M., "A theory of focus interpretation". Natural Language Semantics 1, 75-116, 1992.

[3] Partee, B., "Topics, focus, and quantification". In S. Moore and A. Wyner (eds.): Proc. of SALT 1. 159-187, 1991.

[4] Bartel, C., "Acoustic correlates of second occurrence focus: toward an experimental investigation". In H. Kamp and B. Partee (eds.): Context Dependence in the Analysis of Linguistic Meaning. Amsterdam: Elsevier. 345-361, 2004.

[5] Beaver, D., Clark, B., Flemming, E., Jaeger, T., Wolters, M., "When semantics meets phonetics: acoustical studies of second occurrence focus". Language 83(2): 245-276, 2007.

[6] Howell, J., "Second occurrence focus and the acoustics of prominence". In C. Chang \& H. Haynie. Proceedings of WCCFL 26. Cascadilla Press. 252-260. 2008.

[7] Beckman, M., Pierrehumbert, J., "Intonational structure in Japanese and English". Phonology Yearbook 3, 1986.

[8] Féry, C., and Ishihara, S., "Interpreting second occurrence focus". Ms. University of Potsdam, 2005. Accessed 26/3/08 from http://semanticsarchive.net/.

[9] Boersma, P., Weenink, D., "Praat: doing phonetics by computer". Ver. version. 5.0.13, 2008.

[10] Ladd, R., Intonational phonology. Cambridge University Press, 1996.

[11] Silverman, K., Beckman, M., Pitrelli, J., Ostendorf, M., Wightman, C., Price, P., Pierrehumbert, J., Hirschberg, J., "ToBI: A standard for labelling". Proc. ICSPL, 1992. 